\title{
Identity-based motivation and consumer behavior
}

\author{
Daphna Oyserman \\ Institute for Social Research, University of Michigan, Ann Arbor, MI 48106-1248, USA
}

Available online 27 June 2009

\begin{abstract}
Choices are often identity-based yet the identity-to-choice link is not necessarily obvious for reasons articulated by the identity-based motivation model (Oyserman, D. (2009). Identity-based motivation: Implication for action-readiness, procedural readiness and consumer behavior. Journal of Consumer Psychology). Specifically, which identities are salient and what identities mean in the moment are highly dependent on situational cues. Though they feel stable, identities are dynamically shaped by situational affordances and constraints and this shaping process can occur without conscious awareness. This implies that product use, including use of utilitarian products, can become identity-based, as can both self-constructive and self-destructive choices. Over time, broader identities are more likely to be cued than more narrow ones, though any identity can be cued in the right circumstances. The commentaries apply the model to culture-contingent effects of power (Shavitt, S., Torelli, C. \& Wong, J. (2009). Identity-based motivation: Constraints and opportunities in consumer research. Journal of Consumer Psychology), charitable giving (Aaker, J. \& Akutsu, S. (2009). Why do people give? The role of identity in giving. Journal of Consumer Psychology), and the consequences of salient identities for self-constructive vs. self-destructive choices (Kirmani, A. (2009). The self and the brand. Journal of Consumer Psychology) and this commentary addresses some of the questions they raise.

(C) 2009 Society for Consumer Psychology. Published by Elsevier Inc. All rights reserved.
\end{abstract}

Interested in a cigarette? Feel like bungee jumping? Want something deep fried more than something broiled? People believe that they do not need to seriously weigh the pros and cons of these choices before deciding - they know who they are and who they are directs their choices. In that sense, choices feel identity-based and identity-congruent. To capitalize on this feeling, marketing campaigns attempt to link products and brands to target audience identities by highlighting relevant traits and characteristics, as well as gender, race-ethnicity, age, and culture-relevant values. This linking strategy appears to be common. For example a recent review of advertisements found by-country differences in campaigns, with more collectivistic content found in Eastern countries and more individualistic content found in Western countries, presumably because campaign managers believed that match to assumed cultural values would be helpful (Morling \& Lamoreaux, 2008).

The (often untested) hope in such campaigns is that identitylinked products and brands will be more likely to be chosen by potential consumers. Yet the evidence suggests that matching works only sometimes (e.g., Deshpande \& Stayman, 1994;

E-mail address: daphna.oyserman@umich.edu.
Forehand \& Deshpande, 2001), leaving open the question of when and how identities matter in consumer behavior. The identity-based motivation (IBM) model (Oyserman, 2009) clarifies why attempts to produce identity-based choice by simple matching strategies has proved illusive. All three commentaries (Aaker \& Akutsu, 2009; Kirmani, 2009; Shavitt, Torelli, \& Wong, 2009) draw attention to situations in which identity links work or fail to work. Though space constraints will not allow me to touch on all of the points they raise, I will revisit some of the major themes in this commentary.

First, the IBM model highlights the importance of situations in not only triggering which identities come to mind but also in dynamically constructing what an identity means and which actions are linked to the identity (Oyserman, 2007, 2009; Oyserman, Brickman, Bybee, \& Celious, 2006; Oyserman, Fryberg, \& Yoder, 2007). A triggered African American identity for example, can focus attention on academics (Oyserman, 2008) or not (Oyserman et al., 2006), depending on the context in which it is cued. Thus, though identities feel stable, they are highly sensitive to situational cues. Identities include not only content but also readiness to act and to use procedures congruent with the identity. Depending on situational affordances, action choices may be self-constructive or self-destructive; asocial, pro-social, or antisocial. Identities can be subtly cued without 
conscious awareness. What an accessible identity means is dynamically constructed in the particular context in which it is cued. As a result, while broad identities are more likely to be cued than more narrow ones, any identity can be cued and any behavior-positive or negative, utilitarian or symbolic, can become identity-linked. By ignoring these subtleties, simple matching approaches reduce the likelihood that the advertising campaign produces the desired results.

By arguing that both the content and the associated action and meaning-making potential of any particular identity are dynamically constructed given the affordances and constraints of a particular situation, the IBM model builds on but goes beyond prior theories of working self-concept. It is not only that identities matter only when they are salient. It is also that what an identity means is shaped by immediate situational affordances and constraints; action and meaning-making flow from this contextually-afforded content. Consider an identity as a 'cool' person. What it means to be cool and what actions are connected with coolness depends on what is constrained and afforded in a particular situation. 'Cool' could be a personal trait or a social trait, linked to group membership. Associated 'cool' behaviors could be asocial and risky (e.g., having unprotected sex, smoking cigarettes), pro-social and healthy (e.g., volunteering, surfing) or anything in between (e.g., using an Apple computer).

Take for example two 2009 advertising campaigns that seek to link their product to being cool. One campaign was produced by the AdCouncil for United Way. The other campaign was produced for the CK-One fragrance from the Calvin Klein brand.

The AdCouncil campaign for United Way successfully cues a pro-social version of cool. With Pat Benetar's song "We Belong" as a backdrop, a series of individuals appear on screen one at a time. Each individual differs in age, race-ethnicity, gender and markers of profession and social class. Each is 'cool', looking into the camera and smiling beguilingly while removing clothing (to reveal a white t-shirt emblazoned with the slogan LIVE UNITED). In the final scene, all of the individuals are shown together in their emblazoned t-shirts. The words and graphics cue coolness as a social identity and with the text clarify both the appropriate action (giving) and the appropriate way to make sense of the world (connection and interrelatedness). ${ }^{1}$

In contrast, the fragrance advertisement successfully cues an asocial version of cool as a personal identity to be obtained not by giving but by consuming. In this campaign as well the characters are 'cool'. First, a male model walks alone toward the camera. Gradually a cast of other good looking, thin, multicultural, and racially-ethnically diverse, young male and female models are added to the frame, some enter individually and others in couples. Each model is uniquely and separately

\footnotetext{
${ }^{1}$ From http://www.youtube.com/watch?v=6UYN5QJLPdw, downloaded May 29, 2009. The lyrics: Whatever we deny or embrace for better or for worse, we belong together. The voice overlay: Underneath everything we are. Underneath everything we do. We are all people-Connected, interdependent, united. And when we reach out a hand to one, we influence the condition of all.
}

appealing and charismatic. The song lyrics" ("all around the world, six billion 'me's' ... are beautiful") and graphics cue coolness as a personal identity and clarify appropriate action (fragrance purchase) and the appropriate way to make sense of the world (uniqueness and differentiation).

Both advertisements feel compelling and have spawned blogger response focusing on the appealing 'cool' identity presented. Yet what coolness means is completely different in each campaign. The AdCouncil frames coolness as a social identity, Calvin Klein frames coolness as a personal identity. In both campaigns, coolness is linked to behaving in particular ways and to making sense of the world in particular ways. As these examples demonstrate, failing to take into account what a cool identity means in context would doom efforts to study the impact of a cool identity on behavior. Even if being cool were rated by target participants as an important identity, what it means to be cool and which behaviors fit with being cool are context-dependent.

Cool as an identity-cue appears in other advertisements as well. For example, Apple computers have a series of advertisements in which a cool and competent Apple user engages in cool banter with an uncool and incompetent nonApple user, called 'PC'. Dell struck back with a series of advertisements suggesting that Apple is just too cool and that real people need Dells. In her commentary, Kirmani (2009) asks when identities cue product or brand choice (e.g., I am cool so I will buy an Apple) and when choosing a brand or product creates an identity (e.g., I bought an Apple so I am cool). A partial answer to the questions of whether consumers prefer products that are linked with them and are more persuaded by appeals that are framed in terms of what are assumed to be their core identities seems to be 'it depends'.

These appeals are likely to work when both the identity, and its content and link to action are included in the advertisement but not otherwise, unless the advertisement is able to capitalize on a larger context that was also salient in context at the point of choice. From an identity-based motivation perspective, advertisements (and social influence communications in social marketing) seeking to influence choices by linking to features of identity are more likely to be persuasive if they follow the basic IBM principles (Oyserman, 2009). First, remind target audience members that they have or desire a particular identity, second, frame what the identity means in context and third, constrain behavioral choices to those relevant to the product, brand, or social marketing attempt.

A number of social marketing studies illustrate this point. East Asian participants were more persuaded to reduce caffeine consumption by collectively-focused health messages and European American participants more persuaded by individually-focused health messages, but only when relevant cultural frame was first primed (Uskul \& Oyserman, in press). Cancer awareness leaflets (published by Cancer Research UK) that described prevention strategies increased readiness to take

\footnotetext{
${ }^{2}$ From http://www.youtube.com/watch?v=zmcDpsX4FpQ, downloaded May 29, 2009.
} 
preventive action among participants who described themselves as cautious and prevention-focused if they were first reminded of this identity (Uskul, Keller, \& Oyserman, 2008). White and black youth, but not Latino youth exposed to the national 'truth' anti-smoking campaign featuring white, black and Latino teens challenging tobacco companies' veracity were equally likely to report negative beliefs about tobacco companies. Presumably this was because the ads targeted a nonhierarchical 'wise' identity that was equally relevant to both white and black youth but not Latinos (for details of the study, see Cowell et al. (2009), for further discussion of cultural differences in response to power cues, see Shavitt et al. (2009)).

Lack of attention to these three key features of identity-based motivational processes would explain why for example race- or culture-matching, sometimes but not always influences choice and preference in marketing research. Race-ethnicity matching helps (Greene, 1999) or doesn't help (Whittler, 1991) advertisers. In one set of studies, when detergents were associated with a same race-ethnicity spokesperson (Deshpande \& Stayman, 1994; Forehand \& Deshpande, 2001) whether race-ethnicity matching helped or not depended on whether the identity was likely to be salient in context. Thus, Latino participants sampled from a town in which Latinos were a minority preferred brands linked to a Latino spokesperson whereas Latinos from a town in which Latinos were a majority did not prefer brands linked to a Latino spokesperson.

Similarly elusive effects have been found with cultural frame-matching. In their commentary, Shavitt, Torelli \& Wong (2009) link the IBM model to two aspects of cultural frame, in addition to individualism and collectivism, they focus on how power is culturally conceptualized. Sometimes, but not always, associating products or brands with culturally-congruent values increases attractiveness and purchase intentions. Thus, when benefits to the individual are highlighted, European Americans are more persuaded buy a laundry detergent than when benefits to the family are highlighted; the reverse is true for Koreans, who prefer laundry detergent marketed with communal rather than individual-value focus (Han \& Shavitt, 1994). Yet cultureframing does not always shift choice or may shift choice in ways not predicted by a culture-matching formulation. Both Chinese and American participants were more willing to buy a toothbrush brand advertised with an individualistic frame than a collectivistic frame (Zang \& Gelb, 1996). While Chinese preferred a camera advertised with a collectivistic frame over one advertised with an individualistic frame, framing did not influence purchase choice of Americans (Zang \& Gelb, 1996).

These results highlight that even seemingly central identities are not always salient, do not always mean the same thing, and are not always linked to the same action (Oyserman, Coon, \& Kemmelmeier, 2002; Oyserman, Sorensen, Reber, \& Chen, in press). Rather than making these unjustified assumptions, marketing campaigns are more likely to produce the desired effect if they capitalize on the fact that identities feel stable and important but are in fact highly malleable. While salient identities do predict readiness to take action and make sense of the world in terms of the identity, identities themselves only feel stable, they are actually highly malleable. Similarly, even though action feels identity-based, which actions are identitycongruent depends on situational constraints and affordances. This means that when used effectively, features of the campaign can create identity content in the moment, so that what it means to hold an identity can be transformed by subtle situational cues.

In their commentary, Aaker \& Akutsu (2009) use the IBM model to predict when charitable appeals are likely to work and when they will result in willingness to give money vs. time. Recall that both the charitable giving and the fragrance campaigns used appealing models and lyrics to cue a cool identity that felt real and right, provided a sensible link to action and a clear meaning-making lens. Yet, the meaning, action, and cognitive procedures cued were quite disparate, underscoring both the situational malleability of identity and identity's consequential impact on action and cognitive procedures.

Although often experienced as stable, identity is highly malleable and situation-sensitive so that which aspect of identity comes to mind is a dynamic product of that which is chronically accessible and that which is situationally cued. Moreover, because what is cued is a general mindset rather than a specific content list, identity's impact on action- and procedural-readiness is likely to occur outside of conscious awareness and without systematic processing. In context, selfdestructive behaviors can feel identity-congruent just as much as self-constructive ones can; asocial or antisocial behaviors can feel as identity-based as pro-social ones.

As noted in each of the commentaries (Aaker \& Akutsu, 2009; Kirmani, 2009; Shavitt et al., 2009), the identity-based motivation model thus provides a unified framework that offers some novel insights on identity-driven processes and their outcomes. For instance, although previous theories generally predict that in-group members will perceive their group and its actions positively, the IBM model broadens this perspective to include positive and negative content and behavior perceived as identity-congruent in context. The model outlines the conditions under which identity-congruent behaviors would be enacted even when these behaviors have known negative consequences. Particularly important is the notion that a salient identity can trigger mental processes that guide subsequent action. Making an identity salient activates identity-consistent processes-behaviors as well as ways of making sense of the world. These can operate outside of awareness and can produce in-context behaviors and perceptions that would not otherwise be chosen.

\section{References}

Aaker, J., \& Akutsu, S. (2009). Why do people give? The role of identity in giving. Journal of Consumer Psychology, 19(3), 267-270.

Cowell, A., Farrelly, M., Chou, R., \& Vallone, D. (2009). Assessing the impact of the national 'truth' antismoking campaign on beliefs, attitudes and intent to smoke by race/ethnicity. Ethnicity \& Health, 14, 75-91.

Han, S., \& Shavitt, S. (1994). Persuasion and culture: Advertising appeals in individualistic and collectivistic societies. Journal of Experimental Social Psychology, 30, 326-350.

Deshpande, R., \& Stayman, D. (1994). A tale of two cities: Distinctiveness theory and advertising effectiveness. Journal of Marketing Research, 31, 57-64. 
Forehand, M., \& Deshpande, R. (2001). What we see makes us who we are: Priming ethnic self-awareness and advertising response. Journal of Marketing Research, 38, 336-348.

Greene, C. L. (1999). Ethnic evaluations of advertising. Journal of Advertising, 28, 49-64.

Kirmani, A. (2009). The self and the brand. Journal of Consumer Psychology, 19(3), 271-275.

Morling, B., \& Lamoreaux, M. (2008). Measuring culture outside the head: A meta-analysis of individualism-collectivism in cultural products. Personality and Social Psychology Review, 12, 199-221.

Oyserman, D. (2007). Social identity and self-regulation. In A. Kruglanski, \& T. Higgins (Eds.), Handbook of Social Psychology (pp. 432-453), Second Edition. NY: Guilford Press.

Oyserman, D. (2008). Racial-ethnic self-schemas: Multi-dimensional identitybased motivation. Journal of Research on Personality, 42, 1186-1198.

Oyserman, D. (2009). Identity-based motivation: Implication for actionreadiness, procedural readiness and consumer behavior. Journal of Consumer Psychology, 19(3), 250-260.

Oyserman, D., Brickman, D., Bybee, D., \& Celious, A. (2006). Fitting in matters: Markers of in-group belonging and academic outcomes. Psychological Science, 17, 854-861.
Oyserman, D., Coon, H., \& Kemmelmeier, M. (2002). Rethinking individualism and collectivism: Evaluation of theoretical assumptions and meta-analyses Psychological Bulletin, 128, 3-73.

Oyserman, D, Fryberg, S., \& Yoder, N. (2007). Identity-based motivation and health. Journal of Personality and Social Psychology, 93, 1011-1027.

Oyserman, D., Sorensen, N., Reber, R., \& Chen, S. X. (in press). Connecting and separating mindsets: Culture as situated cognition. Journal of Personality and Social Psychology. doi:10.1037/a0015850.

Shavitt, S., Torelli, C., \& Wong, J. (2009). Identity-based motivation: Constraints and opportunities in consumer research. Journal of Consumer Psychology, 19(3), 261-266.

Uskul, A., \& Oyserman, D. (in press). When message-frame fits salient culturalframe, messages feel more persuasive. Psychology \& Health. doi:10.1080/ 08870440902759156

Uskul, A. K., Keller, J., \& Oyserman, D. (2008). Regulatory fit and health behavior. Psychology \& Health, 23, 327-346.

Whittler, T. (1991). The effect of actor's race in commercial advertising. Journal of Advertising, 20, 54-60.

Zang, Y., \& Gelb, B. (1996). Matching advertising appeals to culture: The influence of products' use conditions. Journal of Advertising, 25, 29-46. 